Bangladesh J. Zool. 41(2): 173-179, 2013

\title{
FOOD CONSUMPTION OF SALTWATER CROCODILE (CROCODYLUS POROSUS) IN A REPTILE FARM OF BANGLADESH
}

\author{
Md. Sakhawat Hossain, M. Firoj Jaman*, Mushtaq Ahmed, \\ Md. Mokhlesur Rahman and Mayen Uddin \\ Department of Zoology, University of Dhaka, Dhaka-1000, Bangladesh
}

\begin{abstract}
An extensive study was conducted on food consumption and feeding behavior of saltwater crocodile (Crocodylus porosus) in the Reptiles Farm Ltd. (RFL) located at Hatiber village, Bhaluka, Mymensingh. The study was mainly based on direct observation and previous data collected by the technicians of the RFL. Average temperature $\left({ }^{\circ} \mathrm{C}\right)$ in the farm area was significantly correlated with average food consumption ( $g$ ) of the hatchlings $(r=0.714, p<0.05, n=12)$. The average temperature and the average food consumption were highest in August and it was $30.5 \pm 5.5{ }^{\circ} \mathrm{C}$ and $45.02 \pm 13.05 \mathrm{~g}$, respectively. Monthly feeding of hatchlings was different in three individual tubs. The highest food consumption was in August although; hatchery's temperature was constant $\left(32^{\circ} \mathrm{C}\right)$. Crocodilians can increase their level of consumption during warmer months of the year while decreasing it in the cooler months. The highest quantity of food was given in October, probably for accumulation of fat in their body which would provide energy in the whole winter season. A total of $93.1 \mathrm{~kg}$ provisioned food was supplied to an adult crocodiles per year. Food consumption of crocodile is temperature dependent and the potentiality of crocodile farming is embedded in it, by considering this factor it may gain prosperity of crocodile farming in our country.
\end{abstract}

Key words: Food consumption, crocodile farm, Bangladesh

\section{INTRODUCTION}

Reptiles Farm Limited (RFL) is the first commercial saltwater crocodile (Crocodylus porosus) farm in Bangladesh, located in Mymensingh district, Bangladesh. RFL was established in 2004 and now nearly 1200 individual crocodiles including hatchlings, juveniles and breeders are present there. All the breeders of RFL are of third generation. The age range of breeders were 15-30 years. RFL fulfils the IUCN (International Union for Conservation of Nature) and CITES (Convention on International Trade in Endangered Species of Wild Fauna and Flora) criteria for crocodile farming. Among 23 crocodile species in the world, saltwater crocodile is the largest species. Bangladesh had three species of crocodiles (Crocodylus porosus, C. palustris and Gavialis gangeticus) (Sarker and Sarker 1988). All species of crocodiles in Bangladesh are protected by the Bangladesh Wildlife Act 1974 (Deodatus 2003) and revised Wildlife Act 2012.

*Corresponding author: mfjaman@yahoo.com 
Saltwater crocodile is known as estuarine crocodile, locally called "Lonapanir Kumir" and only has been surviving in the Sundarbans mangrove forest and surrounding areas with approximately 200 individuals (Khan 1996). Crocodile kept in enclosure without productive goals are known as captive but hatched from eggs laid by breeders for commercial purposes are known as farmed crocodile (Huchjermeyer 2003).

The geophysical and climatic condition of Bangladesh is suitable for crocodile farming as crocodiles had historical breeding ground at this area. Crocodile farming is relatively new concept for the entrepreneurs of Bangladesh and has been getting popularity due to its economic value. Although, farming of this species requires a significant investment for providing facilities and stocks. Crocodile farming has became familiar in the world because of its high demand of skin, meat, bones and also because of tourist attraction. During the last decade the international demand for crocodile skin has increased tremendously which has turned this industry into a lucrative option for entrepreneurs worldwide. However, feeding is one of the greatest challenges for successful operation of a crocodile farm in the third world countries.

Although, crocodiles are poikilothermic animals, their feeding rate depend on air temperature (Huchjermeyer 2003). So that digestive processes of crocodilians are temperature dependent, stomach contraction and proteolytic activities are known to increase with raising temperatures (Trutnau and Sommerlad 2006). No research has yet been conducted regarding the food consumption of hatchlings and adults crocodiles in any place of the country specially in farming condition. Therefore, it is important to study the food consumption and feeding behavior of saltwater crocodiles in captivity that may ultimately help in increasing scientific knowledge.

\section{MATERIAL AND METHODS}

The study was conducted from March 2011 to February 2012 in the Reptiles Farm Ltd. (RFL), Bhaluka, Mymensingh, Bangladesh. Observation were started early in the morning and continued till afternoon. The study was mainly based on direct field observations and some previous data were collected by the farm technicians. Weather data were collected by weather recording devices (thermometer, hygrometer and rain gauge) located at the reptiles farm. All crocodiles of the RFL depend on provisioned food provided from outside the farm. A total of 32 breeder ponds with the volume of 4,334,024.19 cft accumulate with 46 breeder crocodiles. In the RFL, one nursery with three tubs for rearing of hatchlings up to one year was kept under observation. After incubation, hatchlings were transferred from incubator to hatchery 1 after 48 
hours and kept in three equal tubs of same size and provided the same facilities in the same ground. Up to one year, hatchlings were reared at $32^{\circ} \mathrm{C}$ in order to maintain better growth and survival. All the tubs were kept with same temperature, humidity, and volume and kept undisturbed. One technician always provided provisioned food on regular basis. Food was minced before providing to hatchlings. Chicken and beef were the main sources of minced food. In first three months, minced food was provided to the new born hatchlings everyday. Thereafter, they were given provisioned food for 5-6 days per week. Quality and quantity of the minced food were maintained in the hatchery for better development and lowering stress related disease in the farm.

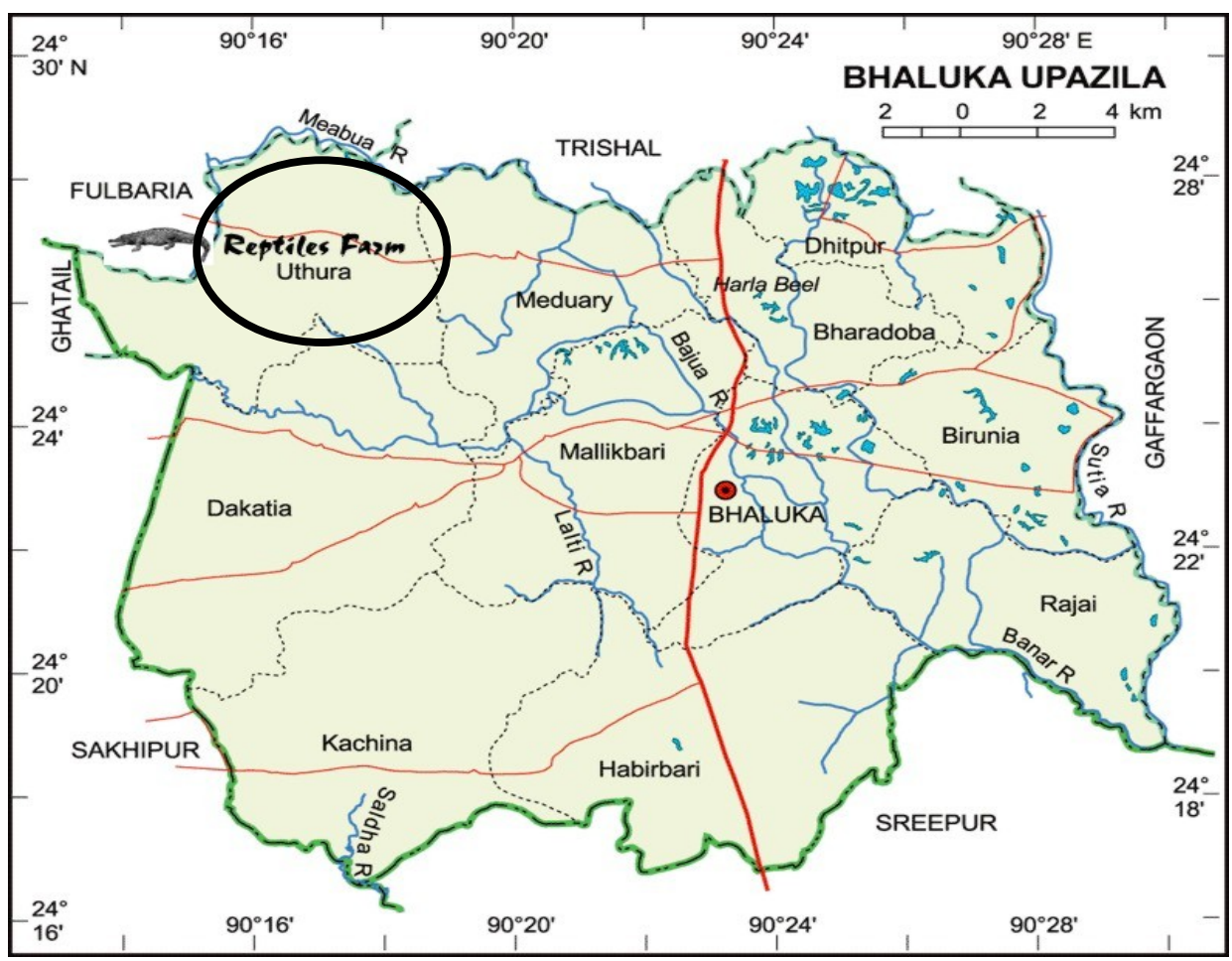

Map 1. Location map showing the study area

All rejected food were collected and measured from tubs and ponds. The farm was equipped with modern facilities (water heater, water flow, generator etc.) for maintaining constant temperature $\left(32^{\circ} \mathrm{C}\right)$ in the hatchery. Breeders were given food at the evening and one feed per week in summer and monsoon. No food was given in winter. Food and feeding data of hatchlings and breeders were also recorded by curator of the farm. The time of feeding and types of food and number of crocodiles were recorded according to date. Feed was given to the 
breeder crocodiles once a week except in winter, when they were kept without food.

Estimation of food consumption of hatchlings and adults (breeders) were calculated by the following formula-

Food consumption $=$ Supplied f1ood - Rejected food $/$ no. of individuals.

MS-excel were used to process and analyze the obtained data. No visitor was allowed during the mating season as it might disturb the crocodiles.

\section{RESULTS AND DISCUSSION}

Feeding of hatchings and average air temperature showed significant relationship $(\mathrm{r}=0.714, \mathrm{p}<0.05, \mathrm{n}=12)$ in different months (Fig. 1).

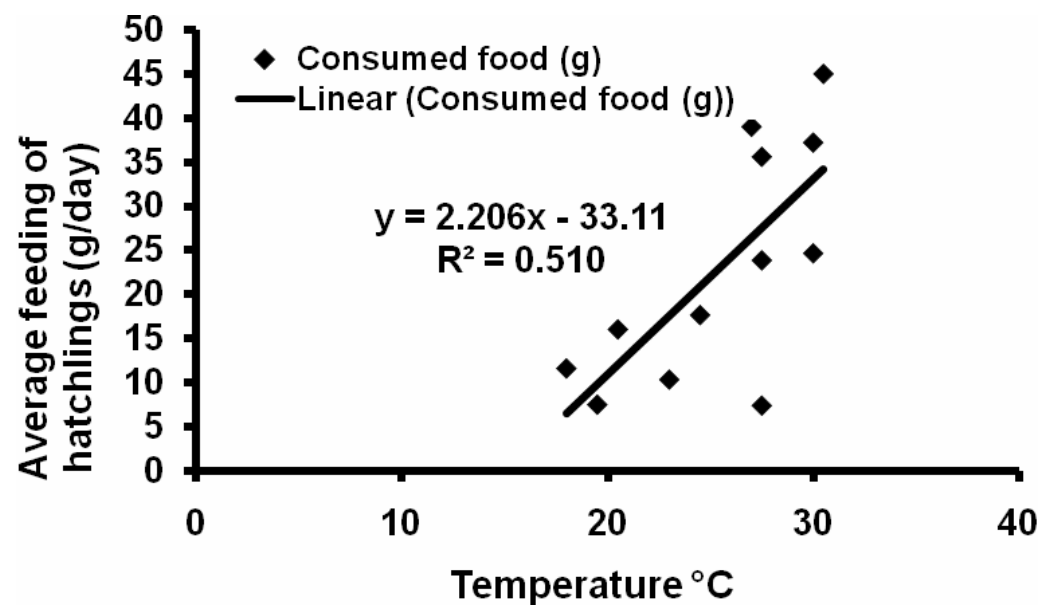

Fig. 1. Linear relationship between monthly average temperature and feeding rate of hatchlings of saltwater crocodile

It was found that both the average temperature and food consumption was the highest in August $\left(30.5 \pm 5.5^{\circ} \mathrm{C}\right.$ and $45.02 \pm 13.75 \mathrm{~g}$, respectively). Average temperature was the lowest $\left(18.0 \pm 9.0^{\circ} \mathrm{C}\right)$ in January and food consumption was the lowest $(7.48 \pm 1.49 \mathrm{~g})$ in October (Table 1). Although hatchlings were kept in artificial condition of $32^{\circ} \mathrm{C}$ but the feeding was regulated throughout the seasons as an instinct characteristic of the crocodiles. Faster growth rate of crocodilians was recorded during the first few months of life and entail feeding at least 6-7 times a week (Whitaker and Andrews 1998). Food was given to the hatchlings regularly up to the age of three months. Young crocodiles appetite returned over about 40 hours as the stomach emptied and total gut clearance time for a meal was 4-5 days (Davenport et al. 1990). 
Table 1. Average temperature of air $\left({ }^{\circ} \mathrm{C}\right)$, age and food consumption of hatchlings of saltwater crocodile in a crocodile farm of Bangladesh

\begin{tabular}{lccc}
\hline Month & $\begin{array}{c}\text { Average temperature } \\
\left({ }^{\circ} \mathrm{C}\right)\end{array}$ & $\begin{array}{c}\text { Average age } \\
\text { (days } \pm 7)\end{array}$ & $\begin{array}{c}\text { Average food } \\
\text { consumption }(\mathrm{g})\end{array}$ \\
\hline October & $27.5 \pm 7.5$ & 31 & $7.48 \pm 1.49$ \\
November & $23.0 \pm 8.0$ & 61 & $10.43 \pm 1.27$ \\
December & $19.5 \pm 9.5$ & 92 & $7.59 \pm 1.33$ \\
January & $18.0 \pm 9.0$ & 123 & $11.69 \pm 2.04$ \\
February & $20.5 \pm 10.5$ & 152 & $16.11 \pm 1.79$ \\
March & $24.5 \pm 7.5$ & 183 & $17.73 \pm 4.7$ \\
April & $27.5 \pm 5.5$ & 213 & $23.92 \pm 3.0$ \\
May & $27.5 \pm 3.5$ & 244 & $35.64 \pm 4.4$ \\
June & $27.0 \pm 3.0$ & 274 & $39.04 \pm 10.25$ \\
July & $30.0 \pm 5.0$ & 305 & $37.25 \pm 1.31$ \\
August & $30.5 \pm 5.5$ & 336 & $45.02 \pm 13.75$ \\
September & $30.0 \pm 5.0$ & 366 & $24.72 \pm 11.09$ \\
\hline
\end{tabular}

Feeding quantity was varied in different tubs and months, though same temperature $\left(32^{\circ} \mathrm{C}\right)$ was maintained. The crocodilians increased their level of consumption during warmer months of the year (from March to September), while decreasing it in the cooler months (Fig. 2). Same trend of feeding behavior of crocodiles was also recorded by Pooley (1990).

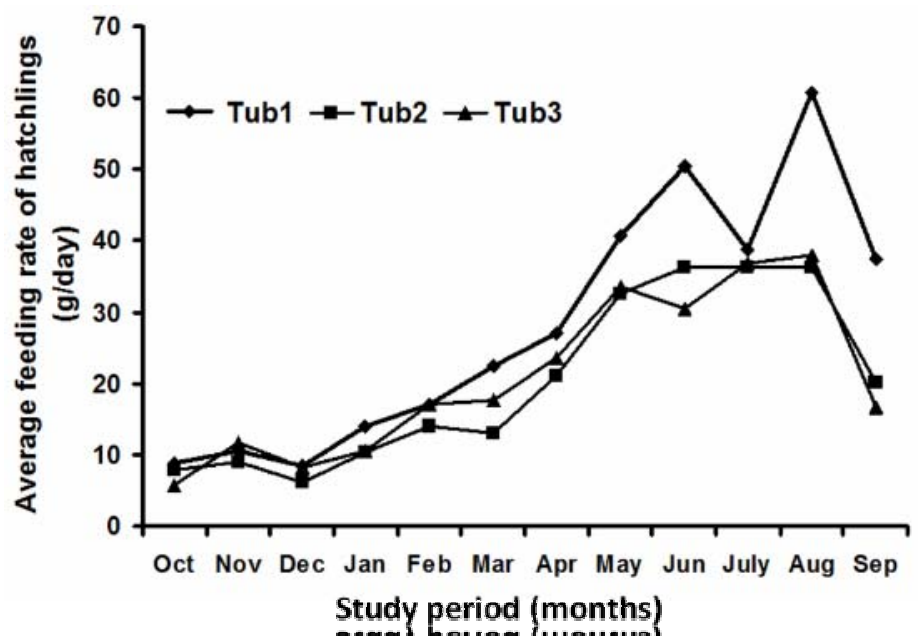

Fig. 2. Feeding rates of hatchlings of saltwater crocodile in three individual tubs

Variability of feeding rate among the individuals rearing in different tubs of the same enclosure has remained unknown. 
In summer (March-June) the supplied feed was $41.4 \mathrm{~kg} /$ individual, in monsoon (July- October) $51.72 \mathrm{~kg} /$ individual and in winter (NovemberFebruary) no feed were given (Fig. 3).

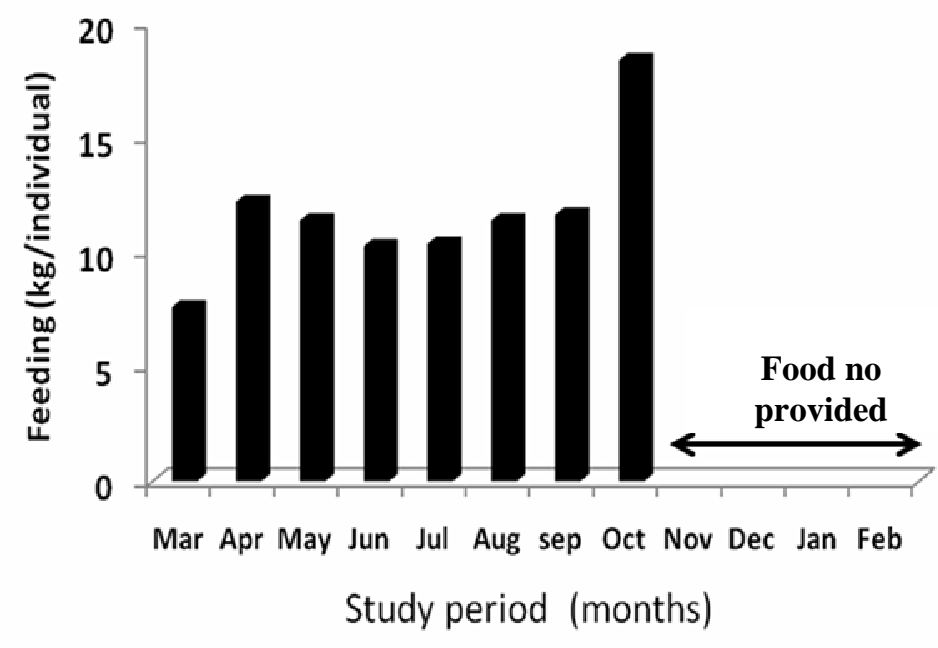

Fig. 3. Monthly feeding rate (kg/individual) of adult saltwater crocodiles (breeders)

Yearly supplied feed was $93.1 \mathrm{~kg} /$ individual. Generally, crocodilians can increase their level of consumption during warmer months of the year while decreasing it in the cooler months (Pooley 1990). Despite accounts of different species in the wild, feeding on carrion and 'storing' food until it is rancid, crocodilians prefer fresh food (Webb and Manolis 1989). It is believed that providing individuals with proper amount of amino acids, vitamins, and minerals, can significantly reduce the detrimental effects of stress in captive crocodilians (Smith and Marais 1994). This is important as, despite the best husbandry and management practices, crocodilians will still inevitably suffer certain levels of stress under captive conditions (Elsey et al. 1994).

Crocodilians are Critically Endangered (CR) in Bangladesh (Annon 2009). Keeping, feeding and breeding them in captivity and reintroduce some in nature are an effective protective measures. The climate of Bangladesh is suitable for crocodile farming. Proper care during hatching, breeding and feeding time would unveil the potentiality of crocodile farming in our country. Our observation suggests that sufficient space is needed for the hatchlings in RFL. Study of feeding behavior of crocodiles in captivity may help better management of crocodiles that may turn help into the well being of captive crocodiles. Therefore, this study might play a vital role to establish a successful crocodile farm in the country. 
Acknowledgements: The authors are grateful to the authority of the Reptiles Farm Limited for giving us the permission to enter into the farm and to collect data. We are also grateful to the Department of Zoology, and Department of Soil, Water and Environment, University of Dhaka for their cooperation and facilities to complete the research. This study was funded by the NSICT fellowship provided by Ministry of Science and Technology.

\section{LITERATURE CITED}

ANNON. 2009. Encyclopedia of flora and fauna of Bangladesh. Asiatic society of Bangladesh. Vol. 25, 204pp.

DAVENPORT, J., GROVE, D.J., CANNON, J., ELLIS, T.R. and STABLES, R. 1990. Food capture, appetite, digestion rate and efficiency in hatchling and juvenile Crocodylus porosus. J. of Zool. 220(4): 569-592.

DEODATUS, F. 2003. Crocodile conservation program in the Bangladesh Sundarban mangrove forest. CSG Newsletter 22(1): 12.

ELESY, R.M., JOANEN, T. and MCNEASE, L. 1994. Captive breeding of alligators and other crocodilians. In: Crocodiles. Proceedings of the $2^{\text {nd }}$ Regional (Eastern Asia, Oceania, Australasia) meeting of the CSG, IUCN Switzerland, pp. 1-27.

HUCHZERMEYER, F.W. 2003. Crocodiles. Biology, husbandry and diseases, CABI publishing, Wallingford, UK, pp. 6.

KHAN, M.A.R. 1996. Bangaladesher Banyaprani. Bangla Academy, Dhaka, Bangladesh, pp.7-183.

POOLEY, T. 1990. Basic crocodile farming ranching methods in remote areas. In: Crocodiles. Proceedings of the 10th Working Meeting of the CSG, IUCN Switzerland, pp. 123-165.

SARKER, S.U. and SARKER, N.J. 1988. Reptiles of Bangladesh. J. Tigre Paper 12(2):6-12.

SMITH, G.A. and MARAIS, J. 1994. Stress in crocodilians - The impact of nutrition. In: Crocodiles. Proceedings of the 12th Working Meeting of the CSG, IUCN Switzerland. 2:2-33.

TRUTNAU, L. and SOMMERLAD, R. 2006. Crocodilians. Their natural history \& captive husbandry. First edition. Edition chimaera Frankfurt am main2006, Andreas S. Brahm, Germany, pp.150.

WEBB, G. and MANOLIS, S.C. 1989. Crocodiles of Australia. Sydney, Reed, pp- 160.

WHITAKER, N. and ANDREWS, H. 1998. Madras Crocodile Bank: an update. In: Crocodiles. Proceedings of the 14th Working Meeting of the CSG, IUCN Switzerland and Cambridge UK, pp. 402-406. 